\title{
Importance of the Order of Addition of the Alumina Precursor and its Type Into Al-SBA-15 Mesoporous Materials for Use as Water Adsorbents
}

\author{
Jéssica de Oliveira Notório Ribeiro ${ }^{a} \mathbb{Q}^{0}$, Daniela Cordeiro Leite Vasconcelos ${ }^{b}$, \\ Wander Luiz Vasconcelos ${ }^{b}$ \\ ${ }^{a}$ Departamento de Engenharia Química, Universidade Federal de Minas Gerais, Av. Antônio Carlos, \\ 6627, Belo Horizonte, MG, Brasil \\ ${ }^{b}$ Departamento de Engenharia Metalúrgica e de Materiais, Universidade Federal de Minas Gerais, Av. \\ Antônio Carlos, 6627, Belo Horizonte, MG, Brasil
}

Received: October 03, 2018; Revised: October 30, 2018; Accepted: November 01, 2018

In the present report, Al-SBA mesoporous materials were investigated for use as water adsorbents. Different precursors for aluminum were investigated: aluminum sulfate and nitrate, boehmite, and aluminum tri-sec-butoxide. Furthermore, three different procedures for addition of the silica and alumina sources were tested. Samples were characterized by nitrogen adsorption to observe their textural characteristics and by thermogravimetric desorption of water to address their performance. The sample synthesized with aluminum tri-sec-butoxide as aluminum precursor and a pre-hydrolysis step of the silica source presented the highest adsorption capacity: $1057 \mathrm{~g} . \mathrm{kg}^{-1}$. It was also observed that water attaches more strongly to Al-containing samples than to pure silica, and that water adsorption capacity is more related to the pore volume of samples than to their surface area. This work has shown that functionalizing SBA-15 materials with aluminum is a promising strategy for producing water adsorbents with improved performance and potential for many applications.

Keywords: alumina, SBA-15, mesoporous silica, sol-gel, water adsorption.

\section{Introduction}

The adsorption of water vapor has many different applications, such as gas dehydration, adsorptive cooling systems ${ }^{1}$ and delivery of drinking water to remote areas ${ }^{2}$. Several new materials are being studied for water adsorption: clays and pillared clays, aluminophosphates, titanium and zirconium silicates ${ }^{3,4}$, mesoporous silica ${ }^{5,6}$, metal-organic frameworks ${ }^{7}$, and composite desiccants composed by hygroscopic salts in inorganic host matrices ${ }^{8}$. In this context, sol-gel SBA-15 mesoporous silica stand out as interesting options for capture of water due to features such as high surface area, controllable morphology and pore size, high concentration of hydroxyl groups on the surface, and possibility of functionalization and insertion of heteroatoms. The insertion of alumina into the mesoporous silica framework, for instance, has been considered beneficial to water adsorption because it may alter the acidity/basicity of the surface, increasing its hydrophilicity ${ }^{9}$. Moreover, the addition of alumina has been said to strengthen the structure of mesopores against corrosion in the presence of water ${ }^{10-13}$.

The sol-gel method for synthesizing Al-added SBA-15 silica samples is somewhat flexible and a great number of variables influence the final characteristics of the materials obtained. For instance, it is possible to use many different chemicals as aluminum source for functionalization. Inorganic

*e-mail: jessicanotorio@gmail.com precursors may be aluminum chloride ${ }^{14}$, nitrate ${ }^{15}$, and sulfate ${ }^{16}$, as well as sodium aluminate ${ }^{17}$. Among the alkoxides which can be employed as organic precursors, the most reported have been aluminum isopropoxide ${ }^{18-20}$, and tri-sec-butoxide (Al-TSB) ${ }^{21-23}$, but tri-tert-butoxide ${ }^{24}$ and tri-n-butoxide are also found. Changing the aluminum source greatly impacts the structure of the so-obtained mesoporous silica-alumina. This was demonstrated by the work of $\mathrm{Li}$ et al. ${ }^{25}$, in which they investigated the effect of various aluminum sources on the morphology and microstructure of Al-SBA-15. They compared four organic and one inorganic precursor of aluminum and observed that features such as surface area, pore volume, pore diameter, aluminum incorporation and even morphology of the particles varied depending on the source used. Their conclusion was that using an organic, liquid aluminum source such as Al-TSB was preferable in their synthetic approach for being able to mix more efficiently with tetraethylorthosilicate (TEOS), which is also a liquid, organic precursor for silica. This was further confirmed by Chorfa et al. ${ }^{23}$, who also explored distinct sources for aluminum: aluminum tri-sec-butoxide, isopropoxide and hydroxide. They also concluded that Al-TSB was the most suitable organic source for co-condensation with TEOS.

Another important aspect in the sol-gel synthesis of Al-SBA-15 type of materials is the order of addition of the silicon and aluminum sources. For instance, the aluminum source can be added before (especially in the case of salt precursors), or after ${ }^{19,23}$ the silicon source. Moreover, Si 
and $\mathrm{Al}$ can be added at the same time separately ${ }^{18,20}$ or pre-mixed ${ }^{24,26}$ into the reaction mixture. To the best of our knowledge, in spite of the potential differences that may arise from varying the order of addition of $\mathrm{Si}$ and $\mathrm{Al}$ sources in Al-SBA-15 synthesis, there is very little amount of work dedicated to investigate the impact of such variations on the porous structure of the materials produced.

Therefore, one of the objectives of this work is to compare distinct orders of addition of TEOS and Al-TSB as silicon and aluminum precursors, respectively. The second objective of the present paper is to increase the existing knowledge about the use of different sources of aluminum. For this, aluminum sulfate, aluminum nitrate, and boehmite were tested in comparison with Al-TSB. Besides carefully evaluating their textural characteristics using nitrogen adsorption, these samples were also assessed as water adsorbents by thermogravimetric desorption of water, which is also an underexplored application in the literature.

\section{Experimental}

\subsection{Materials}

The following chemicals were used without further purification: tetraethylorthosilicate (TEOS, $98 \%$ purity, Aldrich); Pluronic P123 (Aldrich); hydrochloric acid ( $\mathrm{HCl}$, $37 \%$, Aldrich); aluminum sulfate $\left(\mathrm{Al}_{2}\left(\mathrm{SO}_{4}\right)_{3}, 99 \%\right.$ purity, Aldrich), aluminum nitrate $\left(\mathrm{Al}\left(\mathrm{NO}_{3}\right)_{3} \cdot 6 \mathrm{H}_{2} \mathrm{O}\right), 98 \%$ purity, Aldrich); aluminum-tri-sec-butoxide (Al-TSB, $97 \%$ purity, Aldrich); and nitric acid ( $\mathrm{HNO}_{3}, 65 \%$ purity, Aldrich).

\subsection{Synthesis of pure silica SBA-15 (Si-SBA)}

For producing pure silica SBA-15, the surfactant Pluronic $\mathrm{P} 123$ was dissolved into a solution of water and hydrochloric acid with the molar ratio $1 \mathrm{HCl}: 30 \mathrm{H}_{2} \mathrm{O}: 0.003 \mathrm{P} 123$ (acid solution of P123). After the complete dissolution of P123, TEOS was added to the mixture. The final molar ratio was 1 TEOS: $6 \mathrm{HCl}$ : $177 \mathrm{H}_{2} \mathrm{O}$ : 0.017 P123. The hydrolysis and condensation reactions took place in two steps: $24 \mathrm{~h}$ stirring at $40^{\circ} \mathrm{C}$ and $24 \mathrm{~h}$ at $100^{\circ} \mathrm{C}$ in Teflon lined autoclaves. After that, the sample formed was filtered, washed with distilled water and dried at $60^{\circ} \mathrm{C}$. In order to remove the surfactant, the material was heated to $550{ }^{\circ} \mathrm{C}$ at $1{ }^{\circ} \mathrm{C} / \mathrm{min}$, kept at this temperature for $6 \mathrm{~h}$ and cooled to room temperature at $10^{\circ} \mathrm{C} / \mathrm{min}$.

\subsection{Synthesis of Al-SBA-15}

The procedure for synthesizing Al-functionalized samples is identical to that of pure silica SBA-15 described above. The differences are described as follows and summarized in Table 1. The molar ratio aluminum/silicon was kept at 3 $\mathrm{mol} \%$ for all samples, which was determined by preliminary experiments conducted in our laboratory.
Table 1. Conditions of synthesis of Al-SBA samples.

\begin{tabular}{lcc}
\hline Samples & Precursor & Route used \\
\hline $\begin{array}{l}\text { Al-SBA- } \\
\text { sulfate }\end{array}$ & $\mathrm{Al}_{2}\left(\mathrm{SO}_{4}\right)_{3}$ & $\begin{array}{c}\text { Salt dissolution prior to TEOS } \\
\text { addition }\end{array}$ \\
$\begin{array}{l}\text { Al-SBA- } \\
\text { nitrate }\end{array}$ & $\mathrm{Al}_{\left(\mathrm{NO}_{3}\right)_{3}}$ & $\begin{array}{c}\text { Salt dissolution prior to TEOS } \\
\text { addition }\end{array}$ \\
$\begin{array}{l}\text { Al-SBA- } \\
\text { boehmite }\end{array}$ & AlOOH & $\begin{array}{c}\text { Pre-hydrolysis of TEOS followed } \\
\text { by AlOOH addition }\end{array}$ \\
$\begin{array}{l}\text { Al-SBA- } \\
\text { TSB1 }\end{array}$ & Al-TSB & $\begin{array}{c}\text { Mixture between TEOS and } \\
\text { Al-TSB }\end{array}$ \\
$\begin{array}{l}\text { Al-SBA- } \\
\text { TSB2 }\end{array}$ & Al-TSB & $\begin{array}{c}\text { Pre-hydrolysis of TEOS and Al- } \\
\text { TSB, separately }\end{array}$ \\
$\begin{array}{l}\text { Al-SBA- } \\
\text { TSB3 }\end{array}$ & Al-TSB & $\begin{array}{c}\text { Pre-hydrolysis of TEOS followed } \\
\text { by Al-TSB addition }\end{array}$ \\
\hline
\end{tabular}

- $\quad$ Samples with salt precursors (Al-SBA-sulfate and Al-SBA-nitrate): the corresponding salt was dissolved in the acid solution of P123. Then, TEOS was added and the reaction followed as that of Si-SBA.

- Sample with boehmite as precursor (A1-SBAboehmite): TEOS was firstly added to the acid solution of P123 and allowed to react for $1 \mathrm{~h}$ (prehydrolysis step). Then a sol-gel boehmite powder was added to the reaction mixture, which followed the same steps described previously. This sol-gel boehmite was synthesized as follows. Al-TSB and water were mixed at room temperature for 1 $\mathrm{h}$ and then heated up to $85^{\circ} \mathrm{C}$ under stirring for another $4 \mathrm{~h}$. Next, $\mathrm{HNO}_{3}$ was added to the reaction mixture, which was allowed to react for another 24 $\mathrm{h}$ at $85^{\circ} \mathrm{C}$. Then the solution was dried in a stove at $100^{\circ} \mathrm{C}$ and the powder recovered was used as described above.

- Sample with Al-TSB as precursor - route 1 (AlSBA-TSB1): the corresponding amounts of Al-TSB and TEOS were mixed in a beaker in anhydrous conditions and added to the acid solution of P123.

- Sample with Al-TSB as precursor - route 2 (AlSBA-TSB2): The acid solution of P123 was divided in two parts. Al-TSB was added to one half and TEOS to the other. Both solutions were stirred for 1 $\mathrm{h}$ at $40^{\circ} \mathrm{C}$ (separate pre-hydrolysis). Then, the two solutions were poured into one single flask and the reaction continued as described for pure SBA-15.

- Sample with Al-TSB as precursor - route 3 (AlSBA-TSB3): TEOS was added to the acid solution of P123 and stirred for $1 \mathrm{~h}$ at $40^{\circ} \mathrm{C}$ (pre-hydrolysis). Then, Al-TSB was added to the reaction mixture, which followed as previously described.

\subsection{Characterization and performance evaluation}

Nitrogen adsorption tests were carried out in a Micromeritics ASAP 2020 apparatus, using samples previously degassed at $130{ }^{\circ} \mathrm{C}$ for up to $48 \mathrm{~h}$ under vacuum. The specific surface 
area and pore size distribution were assessed by the BET and NLDFT methods, respectively.

The water adsorption capacity evaluation consisted of two parts: an adsorption step inside a humidifier and a desorption step in a thermobalance. For the adsorption step, samples were kept at about $25^{\circ} \mathrm{C}$ in a sealed humidifier for at least one week. The relative humidity was kept at about $100 \%$. For the desorption step, samples were heated from $30{ }^{\circ} \mathrm{C}$ to $500{ }^{\circ} \mathrm{C}$ at $10{ }^{\circ} \mathrm{C} \cdot \mathrm{min}^{-1}$ in a Perkin-Elmer STA6000 thermobalance under nitrogen flow $\left(20 \mathrm{~mL} \cdot \mathrm{min}^{-1}\right)$. The mass lost during the desorption step was associated with the water adsorbed by the sample in the first step. The adsorption capacity was calculated with Equation 1. The error observed for this method was of $5 \%$, according to duplicate measurements performed with selected samples.

Adsorbed amount $\left(\frac{g}{k g}\right)=$

$\frac{\operatorname{Wet} \operatorname{mass}(g)-\operatorname{Dry} \operatorname{mass}(g)}{\operatorname{Dry} \operatorname{mass}(g)} .1000$

Equation 1

\section{Results and Discussion}

\subsection{Nitrogen adsorption results}

Nitrogen adsorption isotherms of the samples produced with inorganic precursors for aluminum are given in Figure 1, together with the pure silica reference. It is possible to observe that the aluminum-added samples displayed an average $23 \%$ smaller surface area when compared to Si-SBA. Among them, the sample synthesized with nitrate preserved the largest surface area $\left(649 \mathrm{~m}^{2} . \mathrm{g}^{-1}\right)$. All curves are of type IV(a) of IUPACs classification ${ }^{27}$, which is characteristic of mesoporous materials, as expected for SBA-15 type of materials. Sample Si-SBA exhibited a H1 hysteresis loop, which indicates a narrow pore size distribution of uniform pores. The Al-SBA samples showed a hysteresis loop intermediate between types $\mathrm{H} 1$ and $\mathrm{H} 2$ (b), indicating more

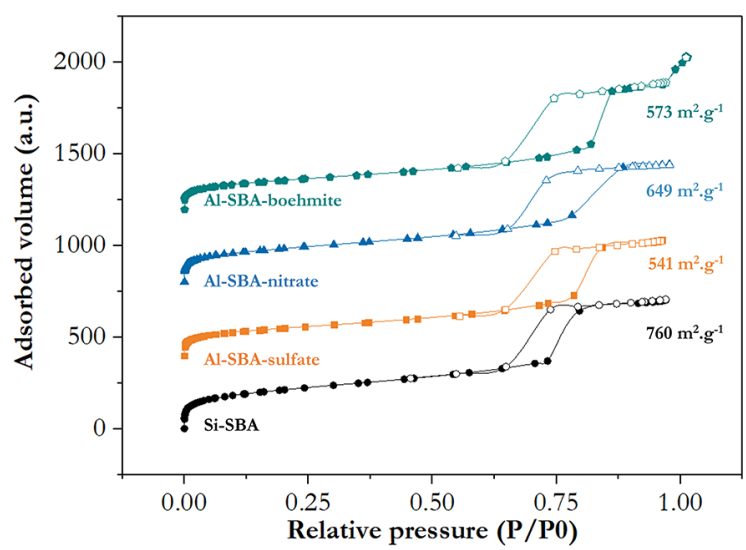

Figure 1. Nitrogen adsorption isotherms of samples with inorganic precursors of aluminum and pure silica SBA.Specific surface areas calculated are also exhibited near their respective isotherms complex pore structures, possibly with pore blocking and neck formation.

The pore size distribution of this group of samples is displayed in Figure 2. The curves given in this Figure showed that the Al-added samples exhibited mesopores of larger sizes when compared to the sample of pure silica. Moreover, it is possible to observe the presence of micropores in all samples (highlighted region) corresponding to the corona present in the mesopore walls, which is characteristic of SBA-15 materials ${ }^{28}$. The sample produced with nanoparticles of solgel boehmite showed the narrowest pore size distribution in the mesopore range, very similar to that of the pure silica. This indicated the formation of a uniform porous structure in Al-SBA-boehmite. Samples produced with nitrate and sulfate showed a partial collapse of the mesophase.

The nitrogen adsorption isotherms of the samples produced with Al-TSB are given in Figure 3 with that of pure silica for comparison. Similarly as those produced with inorganic precursors, samples with $\mathrm{Al}$ addition displayed slightly smaller surface areas - an average of $12 \%$, which is a smaller average loss than that calculated for the first group of

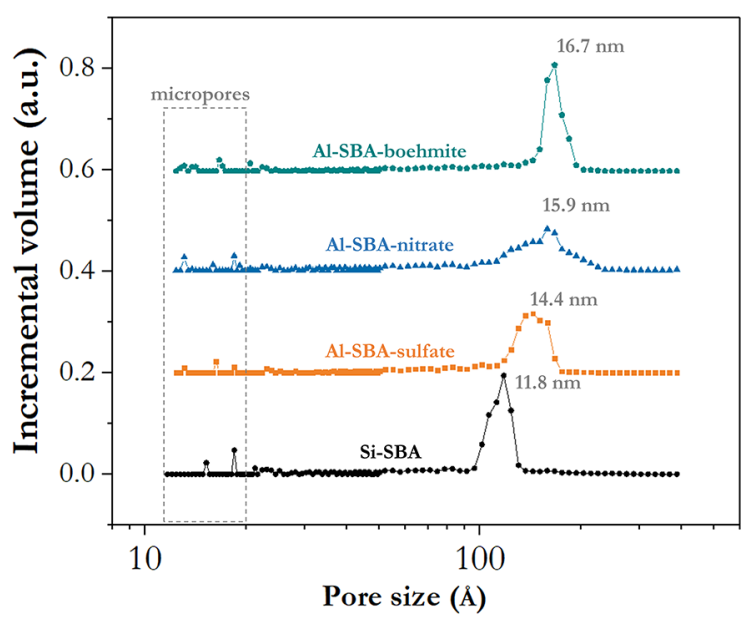

Figure 2. Pore size distributions of samples with inorganic precursors of aluminum and pure silica SBA

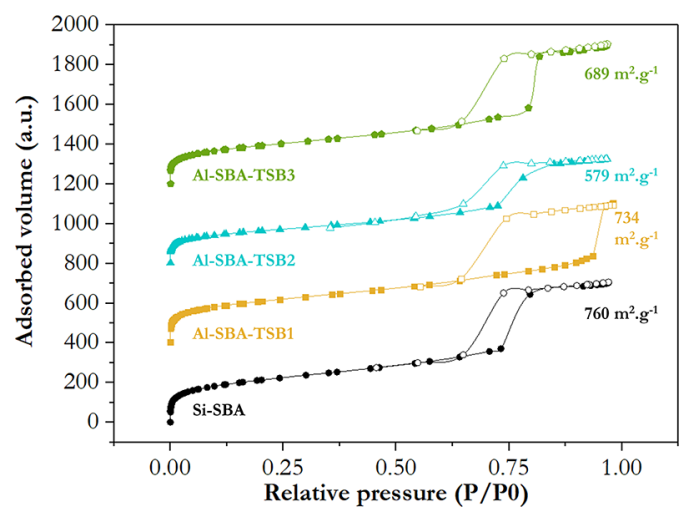

Figure 3. Nitrogen adsorption isotherms of samples with different orders of addition of aluminum precursor and pure silica SBA. Specific surface areas calculated are also exhibited near their respective isotherms. 
samples. Al-SBA-TSB1 displayed the largest surface area in this group, presenting a value only $3 \%$ smaller that Si-SBA.

The shapes of the isotherms varied interestingly. They maintained the type IV(a) of the classification of IUPAC, indicating the formation of mesoporous materials for all samples, but the hysteresis loops displayed some differences. Sample Al-SBA-TSB1 exhibited a wide hysteresis loop indicating the presence of large pore sizes, which can be confirmed by the pore size distribution given in Figure 4. Al-SBA-TSB2 and -TSB3 exhibited intermediates between types $\mathrm{H} 1$ and $\mathrm{H} 2$ (b), which indicated the presence of some irregularity in the pore size distribution and/or the formation of necks in the originally cylindrical pores.

Figure 4 shows the pore size distribution of the samples synthesized with Al-TSB. Sample Al-SBA-TSB1 exhibited pores in the microporous region and also above the detection limit of the equipment, which is $38.7 \mathrm{~nm}$. Due to the shape of the isotherm, it is possible to conclude that this sample presents porosity in the mesopore range. Since this range extends further than the limit of the equipment (up to $50 \mathrm{~nm}$ ), there is a significant probability that this sample presents its major porosity between 38.7 and $50 \mathrm{~nm}$. Sample Al-SBATSB2 exhibited pore sizes in the same range of sizes as the pure silica reference, however in a wider distribution for the mesopore region. Al-SBA-TSB3 presented the narrowest pore size distribution, surpassing even Si-SBA, which indicated the formation of a highly uniform porous structure.

With these two groups of samples analyzed, it was possible to evaluate the influence of two factors in the construction of the porous structure of Al-SBA-15: the type of aluminum precursor and the relative order of addition of the $\mathrm{Si}$ and Al sources. The previously shown results showed that the samples which presented the narrowest pore size distribution in the mesopore range were Al-SBA-TSB3 and Al-SBAboehmite, similarly to pure silica SBA-15. This indicated that the mesopores were better formed in these samples when compared to the others synthesized in this work. However, it is important to highlight that all samples produced exhibited

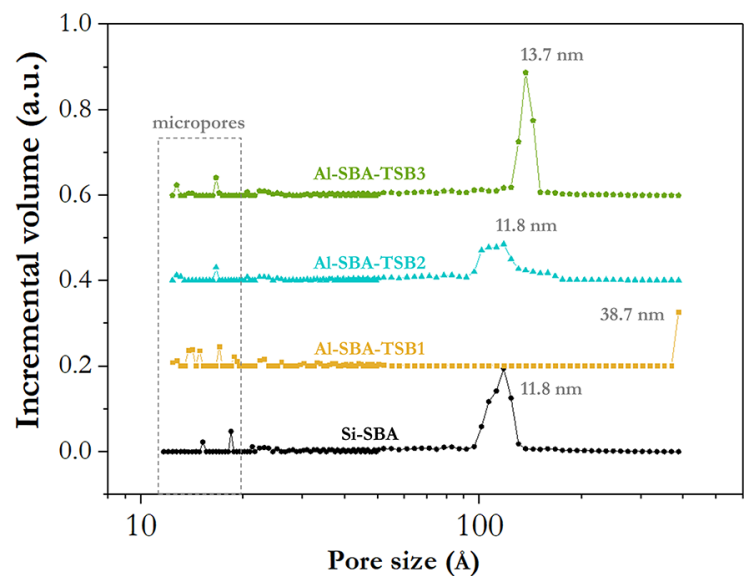

Figure 4. Pore size distributions of samples with different orders of addition of aluminum precursor and pure silica SBA. high values of surface area, which enables them to present significant performances as adsorbents.

It is believed that there are two main factors that can contribute to the distortion of the mesostructure caused by the addition of aluminum into SBA-15. The first of them is related to cooperative self-assembly (CSA) mechanism of formation of SBA-15. In the CSA, the interaction between the surfactant and the ionic species in solution occurs through a $\mathrm{S}^{0} \mathrm{H}^{+} \mathrm{X}^{-} \mathrm{I}^{+}$mechanism, with $\mathrm{S}^{0} \mathrm{H}^{+}$being the surfactant hydrogen bonded to a hydronium ion (which occurs due to the acid $\mathrm{pH}$ of the solution), $\mathrm{X}^{-}$is the chloride ion and $\mathrm{I}^{+}$is the protonated silica ${ }^{29}$. With the introduction of nitrate and sulfate anions in solution, as occurred for samples Al-SBA-sulfate and AlSBA-nitrate for instance, there might be a substitution of the $\mathrm{X}^{-}$positions by these anions intermediating the interaction between the silica species and the surfactant. Since these anions have different sizes and even distinct charges (such as sulfate) than that of the chloride anion, this substitution may impair the geometrical arrangement of the micelles and induce the distortion of the so-formed mesopores. This could cause the results observed for Al-SBA-nitrate and Al-SBA-sulfate. It would be, therefore, preferable to avoid aluminum precursors with such foreign anions in order to diminish this type of disturbance in the structure.

At the same time, a similar phenomenon may occur when $\mathrm{Al}^{3+}$ replaces $\mathrm{Si}^{4+}$ in the $\mathrm{I}^{+}$position. In this case, such substitution is even desirable, because it would enable an isomorphic substitution of silica by aluminum in the framework. However, due to differences in ionic charges, sizes and even coordination capabilities, this replacement by itself may also impair the geometrical arrangement of the micelles. This might have occurred in samples Al-SBA-sulfate, Al-SBAnitrate and Al-SBA-TSB1. Therefore, separating aluminum and silicon ions in the initial stages of micelle organization or removing the aluminum precursors from this step were the strategies adopted for samples Al-SBA-TSB2 (separating sources), Al-SBA-TSB3 and Al-SBA-boehmite (removing Al sources). The results presented herein showed that, nonetheless, only the second strategy was well-succeeded.

The second factor to be considered in this discussion is the faster kinetics of hydrolysis and condensation reactions of Al-TSB when compared to TEOS ${ }^{30}$. If both precursors are added at the same time to the acid solution of the surfactant, Al-TSB reacts instantly upon contact with water, much before silica. This impairs the interaction between the two sources and the homogeneous dispersion of the aluminum into the silica matrix. It also does not allow enough time for the interaction with the surfactant to occur properly ${ }^{31}$. This might have been significant for samples Al-SBA-TSB1 and Al-SBA-TSB2. Therefore, it is also important to use strategies of synthesis which approximate the reaction conditions of the two metal precursors, as used in Al-SBA-TSB3 ${ }^{26}$.

The approach of allowing TEOS to react for $1 \mathrm{~h}$ before introducing an Al source (samples Al-SBA-TSB3 and Al- 
SBA-boehmite) enabled it to be at a more advanced state of reaction before contacting the aluminum precursors, compensating the disparity in their velocities of reaction. At the same time, the pre-hydrolysis step allowed the initial organization of the micelles to develop only in the presence of silica precursors. As commented before, this is also believed to be positive for mesopore formation. Therefore, the preferential order of addition of precursors as revealed by our results is the silicon source before the aluminum source, with an interval of pre-hydrolysis of $1 \mathrm{~h}$.

\subsection{Water desorption results}

The performance for water adsorption was also evaluated for samples presented in the previous section. The analysis consisted of hydrating the samples until saturation in a sealed container and then monitor the mass loss with rising of temperature, as shown in Figure 5. The curves in this figure reveal only one region of mass loss, which is associated to the removal of adsorbed water. When heating silica samples at temperatures above $200{ }^{\circ} \mathrm{C}$, there is also the loss of hydroxyl terminations on the surface ${ }^{32}$, as can be noticed by the gentle inclination on the curves of Figure 5. However, when compared to the mass loss observed below $100{ }^{\circ} \mathrm{C}$, this mass loss becomes insignificant. This way, it

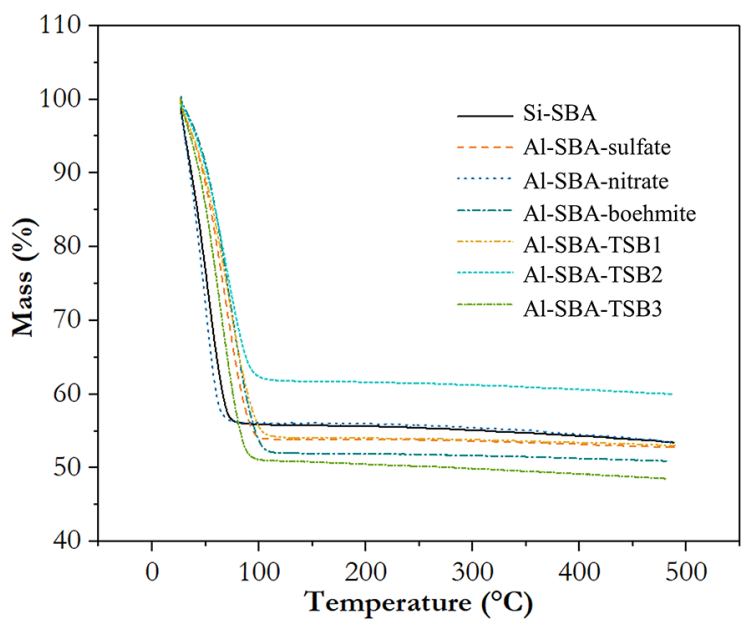

Figure 5. Water desorption thermogravimetry for Al-SBA and Si-SBA samples. was possible to calculate the adsorption capacities of the samples under study, given in Table 2.

Data in this table showed that, in general, samples with alumina addition presented adsorption capacities larger than pure silica, except for Al-SBA-TSB2. This indicates that the insertion of alumina was positive for their overall performance as water adsorbents. In Table 2, it is also possible to observe that the samples which exhibited the highest adsorption capacities were Al-SBA-TSB3 $(1057 \mathrm{~g} / \mathrm{kg})$ and Al-SBAboehmite $(977 \mathrm{~g} / \mathrm{kg})$ - those synthesized with a pre-hydrolysis step of TEOS and which presented the narrowest pore size distribution, as discussed previously. Moreover, the sample with Al-TSB as precursor surpassed the performance of its analogue with boehmite, confirming the tendency found in the literature to consider Al-TSB a more suitable source for this functionalization ${ }^{23,25}$.

The adsorption capacities obtained for these materials can be considered very promising when compared to commercial silica gels, which present a capacity around 400 g. $\mathrm{kg}^{-1}$ 33,34. They also exhibited superior adsorption capacities than many other water adsorbents found in literature, such as the composite adsorbents developed by Zhu et al. ${ }^{35}\left(730 \mathrm{~g} \cdot \mathrm{kg}^{-1}\right)$, Aristov et al. ${ }^{36}\left(750\right.$ g. $\left.\mathrm{kg}^{-1}\right)$, Ristic et al. ${ }^{37}\left(630 \mathrm{~g} . \mathrm{kg}^{-1}\right)$ and Solomon et al. ${ }^{38}\left(223\right.$ g. $\left.\mathrm{kg}^{-1}\right)$. They presented a performance competitive to that of the aerogels synthesized by Knez et al. ${ }^{39}$ (1000 g.kg-1) and Mrowiec-Białon et al. ${ }^{40}$ (1200 g. $\left.\mathrm{kg}^{-1}\right)$. Al-SBA type of material presents the advantage of a simpler and less expensive synthetic process when compared to the production of aerogels.

Another parameter presented in Table 2 is the maximum desorption rate temperature (MDRT). This parameter is obtained from the negative of first derivative of the thermogram (-DTG) and corresponds to the temperature at which this derivative reaches its maximum, i.e. when the desorption process reaches its maximum rate. This temperature is related to the strength of the interaction between water molecules and the substrate and the higher it is, the stronger water is attached to the surface.

In an overall manner, Al-containing samples showed MDRTs up to $20{ }^{\circ} \mathrm{C}$ larger than pure silica (except for AlSBA-nitrate). This indicated that water is more strongly bonded to these materials with $\mathrm{Al}$ and $\mathrm{Si}$ than to that with

Table 2. Parameters obtained in nitrogen adsorption and water desorption tests for Al-SBA and Si-SBA samples. *MDRT stands for "maximum desorption rate temperature".

\begin{tabular}{lccccc}
\hline Sample & $\begin{array}{c}\text { Water adsorption } \\
\text { capacity }\left(\mathrm{g} \cdot \mathrm{kg}^{-1}\right)\end{array}$ & MDRT $\left({ }^{\circ} \mathrm{C}\right) *$ & $\begin{array}{c}\text { Surface area } \\
\left(\mathrm{m}^{2} \cdot \mathrm{g}^{-1}\right)\end{array}$ & $\begin{array}{c}\text { Total pore volume } \\
\left(\mathrm{cm}^{3} \cdot \mathrm{g}^{-1}\right)\end{array}$ & $\begin{array}{c}\text { Pore filling degree } \\
(\%)\end{array}$ \\
\hline Si-SBA & 871 & 54 & 760 & 1.02 & 85 \\
Al-SBA-sulfate & 901 & 71 & 541 & 0.96 & 94 \\
Al-SBA-nitrate & 876 & 49 & 649 & 0.93 & 94 \\
Al-SBA-boehmite & 977 & 75 & 734 & 0.94 & 85 \\
Al-SBA-TSB1 & 885 & 73 & 579 & 0.76 & 94 \\
Al-SBA-TSB2 & 667 & 72 & 689 & 1.02 & 88 \\
Al-SBA-TSB3 & 1057 & 66 & 573 & 1.15 & 104 \\
\hline
\end{tabular}


Si only. This enhancement in water bonding strength by addition of aluminum into silica was also observed by other researchers ${ }^{41,42}$.

In order to investigate which textural parameters were most relevant for water adsorption capacity of the group of samples studied, many parameters such as surface area, pore size and volume of micro and/or mesopores were correlated to the water adsorption capacities obtained. Figure 6 presents the correlations for total surface area and pore volume as examples. The values used for the plots are given in Table 2 .

One can observe in Figure 6 that water adsorption capacity seems to be more related to the samples pore volume than to their specific surface area in the tested conditions (saturated air at atmospheric pressure and $25^{\circ} \mathrm{C}$ ). This result is interesting because the surface area is more often correlated to the adsorption capacity. This occurs because, for many adsorbates, molecule-molecule interactions are much weaker than molecule-surface interactions. This leads to the formation of a monolayer of molecules on the surface of the solid, followed then by the formation of subsequent layers, as it is found for nitrogen adsorption. This is not the case for water, for which molecule-molecule interactions are energetically competitive with surface-molecule bonding. This way, the mechanism of water adsorption as proposed by Maheshwari et al. ${ }^{43}$ occurs by the formation of isles or clusters on the inner walls of the pores. These isles are mainly
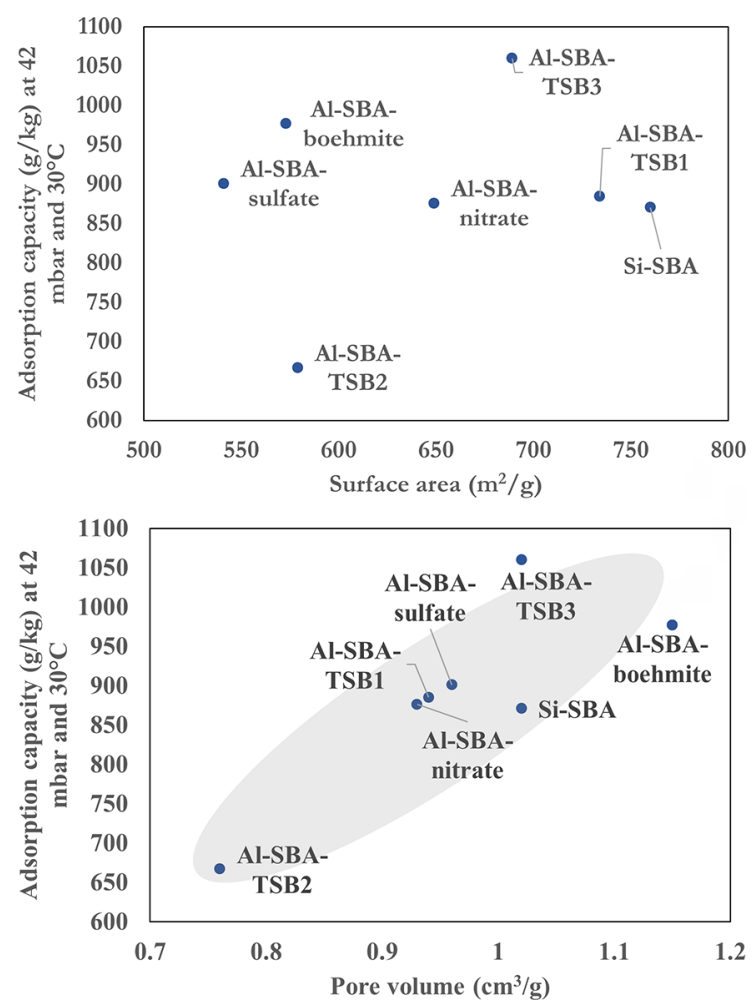

Figure 6. Water adsorption capacity as a function of the surface area (top) and pore volume (bottom) of samples produced. The highlighted region shows the upright tendency of data and is intended to be only a guide to the eyes. concentrated around silanol groups. The number and size of these clusters are initially small, and the large fraction of pore volume is free of water. With the increase in pressure in the system, more and more isles occupy free spaces in the pores. When pressure becomes sufficiently high, these isles become large enough to close the pore clearance ${ }^{44}$, giving rise to the phenomenon of capillary condensation in the mesopores. If the pressure of water available in the system continues to rise (as it is the case of the conditions used in this study), water can fill up the entire pore volume available on the samples. This way, the relationship between pore volume and water adsorption capacity is coherent with the nature of these materials and is corroborated by other researchers ${ }^{45}$.

This can be further discussed using the values of pore filling degree, given in Table 2. The pore filling degree is the fraction of the total pore volume of the sample which is occupied by water at $25^{\circ} \mathrm{C}$, and its calculation is described in detail in the work of Schreiber et al. ${ }^{46}$. Values in Table 2 showed that at least $85 \%$ of the pore volume of the samples was filled with water in the conditions analyzed, confirming the previous discussion. Moreover, most samples with Al addition exhibited a larger pore filling degree than pure silica (average of $93 \%$ against $85 \%$ of Si-SBA). This also suggests that the presence of $\mathrm{Al}$ enhanced the attractiveness of the materials towards water molecules, enabling to withhold more water when exposed to the same adsorption conditions. This seems to have been particularly true for sample Al-SBATSB3, which exhibited $104 \%$ of pore filling degree. This means that not only the entire pore volume was filled, but an external layer of water was also formed during adsorption.

In summary, results have shown that the optimization of the porous structure of Al-SBA materials is of paramount importance for their water adsorption behavior. For instance, large pore volume and uniformity of pore diameters have been associated to the highest adsorption capacities under the conditions evaluated. This further justifies the exploration of sol-gel synthesis parameters such as those studied herein.

\section{Conclusions}

This work has developed Al-SBA mesoporous materials for use as water adsorbents. Among the different precursors tested, it was observed that those with anions such as nitrate and sulfate could bring additional damage to the organization of the porous structure of the resulting materials. Moreover, distinct orders of addition of the $\mathrm{Si}$ and $\mathrm{Al}$ precursors in the sol-gel synthesis were tested. The nitrogen adsorption results showed that the preferential order of addition of the metal sources in the synthetic strategy used is introducing Si first and then Al, with a pre-hydrolysis pause in between. The tests of water desorption showed that samples which exhibited the most uniform porous structure presented the highest water adsorption capacities, which demonstrated the 
importance of this study in light of the optimization of the performance of such materials. The sample synthesized with Al-TSB and the pre-hydrolysis step presented the highest adsorption capacity among the adsorbents developed: 1057 g. kg-1 . It was also confirmed that water attaches more strongly to Al-containing samples than to pure silica, and that water adsorption capacity seems to be more related to the pore volume of samples than to their surface area. This work has shown that functionalizing SBA-15 materials with aluminum is a promising strategy for producing water adsorbents with improved performance and potential for many applications.

\section{Acknowledgements}

The authors acknowledge financial support from Equinor and "Coordenação de Aperfeiçoamento de Pessoal de Nível Superior" (CAPES - Brazil). The authors also thank "Agência Nacional do Petróleo, Gás Natural e Biocombustíveis" (ANP - Brazil).

\section{References}

1. Saha BB, Chakraborty A, Koyama S, Aristov YI. A new generation cooling device employing $\mathrm{CaCl}_{2}$-in-silica gel-water system. International Journal of Heat and Mass Transfer. 2009;52(1-2):516-524.

2. Ji JG, Wang RZ, Li LX. New composite adsorbent for solardriven fresh water production from the atmosphere. Desalination . 2007;212(1-3):176-182.

3. Mirajkar SP, Thangaraj A, Shirakar VP. Sorption properties of titanium silicate molecular sieves. The Journal of Physical Chemistry. 1992;96(7):3073-3079.

4. Rakshe B, Ramaswamy V, Ramaswamy AV. Crystalline, Microporous Zirconium Silicates with MEL Structure. Journal of Catalysis. 1996;163(2):501-505.

5. Liang S, Xu J, Chen J. Study on adsorption of water in MCM41 containing metal ions by molecular dynamic simulations. Journal of Thermal Science. 2004;13(2):187-192.

6. de Leeuw NH, Purton JA, Parker SC, Watson GW, Kresse G. Density functional theory calculations of adsorption of water at calcium oxide and calcium fluoride surfaces. Surface Science. 2000;452(1-3):9-19.

7. Canivet J, Fateeva A, Guo Y, Coasne B, Farrusseng D. Water adsorption in MOFs: fundamentals and applications. Chemical Socity Reviews. 2014;43(16):5594-5617.

8. Zheng X, Ge TS, Wang RZ. Recent progress on desiccant materials for solid desiccant cooling systems. Energy. 2014;74:280-294.

9. Ng EP, Mintova S. Nanoporous materials with enhanced hydrophilicity and high water sorption capacity. Microporous and Mesoporous Materials. 2008;114(1-3):1-26.
10. Shen SC, Kawi S. MCM-41 with Improved Hydrothermal Stability: Formation and Prevention of Al Content Dependent Structural Defects. Langmuir. 2002;18(12):4720-4728.

11. Mokaya R. Influence of pore wall thickness on the steam stability of Al-grafted MCM-41. Chemical Communications. 2001;(7):633-634.

12. Mokaya R, Jones W. Aluminosilicate mesoporous molecular sieves with enhanced stability obtained by reacting MCM-41 with aluminium chlorohydrate. Chemical Communications. 1998;(17):1839-1840.

13. Kim JM, Kwak JH, Jun S, Ryoo R. Ion Exchange and Thermal Stability of MCM-41. The Journal of Physical Chemistry. 1995;99(45):16742-16747.

14. Bhange P, Bhange DS, Pradhan S, Ramaswamy V. Direct synthesis of well-ordered mesoporous Al-SBA-15 and its correlation with the catalytic activity. Applied Catalysis A: General. 2011;400(1-2):176-184.

15. Wu ZY, Wang HJ, Zhuang TT, Sun LB, Wang YM, Zhu JH. Multiple Functionalization of Mesoporous Silica in One-Pot: Direct Synthesis of Aluminum-Containing Plugged SBA-15 from Aqueous Nitrate Solutions. Advanced Functional Materials. 2008;18(1):82-94.

16. Jiang Y, Geng T, Li Q. Synthesis of stearic acid triethanolamine ester over Al-SBA-15. Journal of Porous Materials. 2012;19(3):369374.

17. Talha Z, Bachir C, Ziri S, Bellahouel S, Bengueddach A, Villièras F, et al. Al-Rich Ordered Mesoporous Silica SBA15 Materials: Synthesis, Surface Characterization and Acid Properties. Catalysis Letters. 2017;147(8):2116-2126.

18. Xing S, Lv P, Fu J, Wang J, Fan P, Yang L, et al. Direct synthesis and characterization of pore-broadened Al-SBA-15. Microporous and Mesoporous Materials. 2017;239:316-327.

19. Ahmed K, Rehman F, Pires CTGVMT, Rahim A, Santos AL, Airoldi C. Aluminum doped mesoporous silica SBA-15 for the removal of remazol yellow dye from water. Microporous and Mesoporous Materials. 2016;236:167-175.

20. van Grieken R, Escola JM, Moreno J, Rodríguez R. Direct synthesis of mesoporous M-SBA-15 (M = Al, Fe, B, Cr) and application to 1-hexene oligomerization. Chemical Engineering Journal. 2009;155(1-2):442-450.

21. Chang F, Wang G, Xie Y, Zhang M, Zhang J, Yang HJ, et al. Synthesis of TiO2 nanoparticles on mesoporous aluminosilicate Al-SBA-15 in supercritical CO2 for photocatalytic decolorization of methylene blue. Ceramics International. 2013;39(4):3823-3829.

22. Parlett CMA, Durndell LJ, Machado A, Cibin G, Bruce DW, Hondow NS, et al. Alumina-grafted SBA-15 as a high performance support for Pd-catalysed cinnamyl alcohol selective oxidation. Catalysis Today. 2014;229:46-55.

23. Chorfa N, Hamoudi S, Belkacemi K. Conjugated linoleic acid formation via heterogeneous hydrogenation/isomerization of safflower oil over mesostructured catalysts. Applied Catalysis A: General. 2010;387(1-2):75-86. 
24. Duan J, Han J, Sun H, Chen P, Lou H, Zheng X. Diesel-like hydrocarbons obtained by direct hydrodeoxygenation of sunflower oil over Pd/Al-SBA-15 catalysts. Catalysis Communications. 2012;17:76-80.

25. Li W, Huang SJ, Liu SB, Coppens MO. Influence of the Al Source and Synthesis of Ordered Al-SBA-15 Hexagonal Particles with Nanostairs and Terraces. Langmuir. 2005;21(5):2078-2085.

26. Li Y, Zhang W, Zhang L, Yang Q, Wei Z, Feng Z, et al. Direct Synthesis of Al-SBA-15 Mesoporous Materials via HydrolysisControlled Approach. The Journal of Physics Chemistry B. 2004;108(28):9739-9744.

27. Thommes M, Kaneko K, Neimark AV, Olivier JP, RodriguezReinoso F, Rouquerol J, et al. Physisorption of gases, with special reference to the evaluation of surface area and pore size distribution (IUPAC Technical Report). Pure and Applied Chemistry. 2015;87(9-10):1051-1069.

28. Janus R, Natkanski P, Wadrzyk M, Dudek B, Gajewska M, Kustrowski P. Synthesis of pseudo-CMK-3 carbon replicas by precipitation polycondensation of furfuryl alcohol in the pore system of SBA-15 detemplated using $\mathrm{KMnO}_{4}$. Materials Today Communications. 2017;13:6-22.

29. Huirache-Acuña R, Nava R, Peza-Ledesma C, Lara-Romero J, Alonso-Núñez G, Pawelec B, et al. SBA-15 Mesoporous Silica as Catalytic Support for Hydrodesulfurization Catalysts-Review. Materials (Basel). 2013;6(9):4139-4167.

30. Brinker CJ, Scherer GW. Sol-Gel Science: The Physics and Chemistry of Sol-Gel Processing. San Diego: Academic Press; 1990.

31. Nunes SC, Almeida P, Bermudez VZ. Ordered Mesoporous Sol - Gel Materials: From Molecular Sieves to Crystal-Like Periodic Mesoporous Organosilicas. In: Levy D, Zayat M, eds. The Sol-Gel Handbook - Synthesis, Characterization, and Applications. 1st ed. New York: Wiley; 2015. p. 1-30.

32. Zhuravlev LT. The surface chemistry of amorphous silica. Zhuravlev model. Colloids and Surfaces A: Physicochemical and Engineering Aspects. 2000;173(1-3):1-38.

33. Chua HT, Ng KC, Chakraborty A, Oo NM, Othman MA. Adsorption Characteristics of Silica Gel + Water Systems. Journal of Chemical \& Engineering Data. 2002;47(5):11771181 .

34. Cevallos ORF. Adsorption Characteristics of Water and Silica Gel System for Desalination Cycle. [Thesis]. Thuwal: King Abdullah University of Science and Technology; 2012.
35. Zhu D, Wu H, Wang S. Experimental study on composite silica gel supported $\mathrm{CaCl} 2$ sorbent for low grade heat storage. International Journal of Thermal Sciences. 2006;45(8):804-813.

36. Aristov YI, Restuccia G, Cacciola G, Parmon VV. A family of new working materials for solid sorption air conditioning systems. Applied Thermal Engineering. 2002;22(2):191-204.

37. Ristić A, Maučec D, Henninger SK, Kaučič V. New two-component water sorbent $\mathrm{CaCl}_{2}-\mathrm{FeKIL} 2$ for solar thermal energy storage. Microporous and Mesoporous Materials. 2012;164:266-272.

38. Solomon I, Ribeiro AM, Santos JC, Loureiro JM, Rodrigues AE, Sandu I, et al. Adsorption equilibrium of water vapor on activated carbon and alumina and carbon and alumina impregnated with hygroscopic salt. Turkish Journal of Chemistry. 2013;37:358-365.

39. Knez Ž, Novak Z. Adsorption of Water Vapor on Silica, Alumina, and Their Mixed Oxide Aerogels. Journal of Chemical \& Engineering Data. 2001;46(4):858-860.

40. Mrowiec-Bialon J, Jarzebski AB, Lachowski AI, Malinowski JJ. Two-component aerogel adsorbents of water vapour. Journal of Non-Crystalline Solids. 1998;225:184-187.

41. Perez-Beltran S, Balbuena PB, Ramírez-Caballero GE. Surface Structure and Acidity Properties of Mesoporous Silica SBA-15 Modified with Aluminum and Titanium: First-Principles Calculations. The Journal of Physics Chemistry C. 2016;120(32):18105-18114.

42. Wei X, Wang W, Xiao J, Zhang L, Chen H, Ding J. Hierarchically porous aluminosilicates as the water vapor adsorbents for dehumidification. Chemical Engineering Journal. 2013;228:11331139.

43. Maheshwari P, Gorgol M, Kierys A, Zaleski R. Positron Probing of Liquid-free Volume to Investigate Adsorption-Desorption Behavior of Water in Two-Dimensional Mesoporous SBA-3. The Journal of Physics Chemistry C. 2017;121(32):17251-17262.

44. Grünberg B, Emmler T, Gedat E, Shenderovich I, Findenegg $\mathrm{GH}$, Limbach $\mathrm{HH}$, et al. Hydrogen bonding of water confined in mesoporous silica MCM-41 and SBA-15 studied by $1 \mathrm{H}$ solid-state NMR. Chemistry - A European Journal. 2004;10(22):5689-5696.

45. Saliba S, Ruch P, Volksen W, Magbitang TP, Dubois G, Michel B. Combined influence of pore size distribution and surface hydrophilicity on the water adsorption characteristics of microand mesoporous silica. Microporous and Mesoporous Materials. 2016;226:221-228.

46. Schreiber A, Ketelsen I, Findenegg GH. Melting and freezing of water in ordered mesoporous silica materials. Physical Chemistry Chemical Physics. 2001;3(7):1185-1195. 